\title{
Undesired Phenotypic and Genetic Trend for Stillbirth in Danish Holsteins
}

\author{
M. Hansen, ${ }^{1,2,3}$ I. Misztal, ${ }^{4}$ M. S. Lund, ${ }^{1}$ J. Pedersen, ${ }^{2}$ and L. G. Christensen ${ }^{3}$ \\ ${ }^{1}$ Danish Institute of Agricultural Sciences, Department of Animal Breeding and Genetics, \\ Research Centre Foulum, P.O. Box 50, DK-8830 Tjele, Denmark \\ ${ }^{2}$ Danish Agricultural Advisory Service, National Centre, Danish Cattle Federation, \\ Udkærsvej 15, Skejby, 8200 Aarhus N, Denmark \\ ${ }^{3}$ The Royal Veterinary and Agricultural University, Department of Animal Science and Animal Health, \\ Grønnogardsvej 2, DK-1870, Frederiksberg C, Denmark \\ ${ }^{4}$ University of Georgia, Department of Animal and Dairy Science, 354 \\ Animal and Dairy Science Complex, Athens 30602
}

\begin{abstract}
The primary aim of this study was to evaluate the phenotypic and genetic trends for stillbirth in Danish Holsteins. Trends of calving difficulty and calf size were also evaluated. The second aim was to compare predicted transmitting abilities (PTA) of sires for stillbirth using a linear and a threshold model. Direct and maternal genetic effects were modeled by fitting correlated additive genetic effects of the sire and the maternal grandsire (MGS). For both the calf and the dam, covariates of breed proportions of Holstein-Friesian (HF) and the heterozygosity between $\mathrm{HF}$ and the original Danish Black and White (ODBW) were included. Records from 1.8 million first-calving Danish Holstein cows calving from 1985 to 2002 were used. In this period, the overall frequency of stillbirth increased from 0.071 to 0.090 . An unfavorable genetic trend of stillbirth was found for both the direct and maternal effect. The background for the genetic trends was an intense use of HF sires as sires of sons, which increased the proportion of $\mathrm{HF}$ genes to $94 \%$ in the Danish Holstein calves born in 2002. The effect of the imported HF genes was higher direct effects of calf size, calving difficulty, and stillbirth compared with the ODBW genes. The maternal effect of stillbirth was poorer for HF than for ODBW even though HF had a better maternal calving performance than ODBW. The threshold and the linear models showed almost similar predictions of transmitting abilities of sires.
\end{abstract}

(Key words: stillbirth, calving ease, calf size, genetic trend)

Abbreviation key: CVM = complex vertebral malformation, $\mathbf{H F}=$ Holstein-Friesian, $\mathbf{M A P}=$ maximum a posteriori, MGS = maternal grandsire, $\mathbf{O D B W}=$ original Danish Black and White.

Received September 25, 2003

Accepted December 17, 2003.

Corresponding author: M. Hansen; e-mail: mxh@landscentret.dk.

\section{INTRODUCTION}

In Denmark and Sweden, the stillbirth rate for Holstein cows at first calving has increased during the last decades and is now around 10\% (Nielsen et al., 2002; Steinbock et al., 2003). This is nearly twice as high as in other Nordic dairy breeds (Swedish Red, Danish Red, and Danish Jersey) (Nielsen et al., 2002; Steinbock et al., 2003). In the beginning of the 1970s, the importation of Holstein-Friesian (HF) semen from North America for use in the Danish Black and White population was initiated. This started a dramatic change in the genetic composition of the Danish Black and White population. Today, the breed is named Danish Holstein, as most genes from the original Danish Black and White (ODBW) population have been displaced by HF genes. It is likely that this change of genetic background has lead to an unfavorable genetic change, which could explain the reason for the observed phenotypic increase in stillbirths in Danish Holstein. Therefore, the genetic change in stillbirth needs to be established. In HF in the US, indications of an unfavorable trend of direct and maternal effects of stillbirth have been found (Meyer et al., 2001), but no genetic trend was found in the Netherlands (Harbers et al., 2000). To understand the genetic development of Danish Holstein, knowledge about the genetic differences between HF and ODBW is also relevant. However, these breed differences are not relevant for future breeding decisions because only a small population $(<200$ cows $)$ of purebred ODBW cows exists today.

The rate of stillbirth is highest for first-calving cows, partly because of a disproportion between the size of the calf and the size of the pelvic area (fetopelvic-complex), which causes a difficult calving (Meijering, 1984). Therefore, it is relevant to examine stillbirth, calving difficulty, and calf size, which have been recorded on Danish dairy farms since 1985. By including calving difficulty and calf size, it is possible to explain whether the increase in stillbirths is associated with an increase in calving difficulties and calf size. Calving difficulties 
are, from an economic point of view, also important, as they are associated with stillbirths, veterinary assistance, and additional work. They also reduce the dams' milk production and fertility and increase the risk of culling (Dematawewa and Berger, 1997).

Linear models are currently applied for the national genetic evaluation of stillbirth and calving difficulty in Denmark (Danish Cattle Federation, 2003). A threshold model (Gianola and Foulley, 1983) may be a more valid model because it takes into account the categorical nature of these traits. However, high correlations $(>0.92)$ between PTA from a linear and a threshold model have been found (Weller et al., 1988; Hagger and Hofer 1990). Threshold models have been implemented for official genetic evaluations of calving ease in France (Ducrocq, 2000) and in the US (Wiggans et al., 2003), but none of the countries that have an official genetic evaluation for stillbirth are currently using threshold models (Pasman and Reinhardt, 2002).

The major objective of this study was to estimate the genetic trend of stillbirth for first-calving Danish Holstein cows using a threshold model. The hypothesis was that an unfavorable genetic trend for stillbirth existed. As stillbirth is genetically associated with calving difficulty and calf size (Meijering, 1984; Hansen et al., 2003); the genetic trends of these traits were also computed to accomplish a better understanding of the stillbirth trend. The second objective was to compare PTA of stillbirth from a linear model with PTA from a threshold model.

\section{MATERIALS AND METHODS}

\section{Data}

Data from first-calving Holstein cows used for the national evaluation of calving traits (Danish Cattle Federation, 2003) were extracted from the national cattle database. The data were recorded by farmers for all cows. Stillbirth was defined in two categories: $1=$ survived $24 \mathrm{~h}$ after birth and $2=$ dead at birth or within $24 \mathrm{~h}$ after birth. The calving difficulty consisted of 4 ordered categories: 1 = easy with no help, 2 = easy with assistance, 3 = difficult but without veterinary assistance, and $4=$ difficult with veterinary assistance. Calf size consisted of 4 ordered categories: $1=$ small, $2=$ just below medium, $3=$ just above medium, and $4=$ large. Only records of calves with a known AI sire and maternal grandsire (MGS) and with a gestation period $>240 \mathrm{~d}$ were used. Records from multiple births, from abortions, with unknown sex of calf, or with a calving age of the dam $<21$ mo were excluded. All cows that had a calving age $>35$ mo were grouped in one subclass. Finally, herd-year subclasses with $<6$ records were excluded. The final data set included almost 1.8 million records of stillbirth and almost 1.5 million records of calving difficulty and calf size (Table 1).

The average proportion of $\mathrm{HF}$ genes in the calves was 0.58 in 1985 and 0.94 in 2002 (Figure 1). The average proportion of $\mathrm{HF}$ genes in the dams was 0.43 in 1985 and 0.90 in 2002. Heterosis between HF and ODBW was assumed to arise from effects of dominance only and, therefore, was proportional to the degree of heterozygosity. The degree of heterozygosity (h) was obtained for each individual (calf and dam) as $\mathrm{h}=$ psire $_{\mathrm{HF}} \times$ pdam $_{\mathrm{ODBW}}+$ psire $_{\mathrm{ODBW}} \times$ pdam $_{\mathrm{HF}}$, where psire and pdam were the proportions of genes from the breeds (HF or ODBW) in the sire and the dam of the individual. The breed proportions of the individuals were traced using all available pedigree information. As a result of the increasing proportion of HF in Danish Holstein, the heterozygosity decreased during the period (Figure 1). From 1985 to 2002, the average degree of heterozygosity in the calves decreased from 0.53 to 0.11 and from 0.57 to 0.20 in the dams.

\section{Statistical Methods}

Estimates (predictions) of location parameters were obtained using a two-step approach as recommended by Wang et al. (1997). First, dispersion parameters were estimated in a Bayesian analysis with Gibbs sampling; this was carried out by Hansen et al. (2003, 2004) using a subset of the data. Second, the full data set was used to estimate location parameters as the joint posterior mode conditional on the estimated dispersion parameters (maximum a posteriori [MAP]) (Gianola and Foulley, 1983). A full Bayesian analysis with Gibbs sampling taking the uncertainty of all parameters into account would be the preferred method. However, the MAP approach is recommended for national genetic evaluations (Wang et al., 1997) because applying Gibbs sampling to very large data sets is a very time-demanding, computational task. When MAP estimates are based on accurate estimates of dispersion parameters, they are almost identical to estimates from a model where all uncertainties of parameters are taken into account (Wang et al., 1997).

Threshold model. In the threshold model, the observed outcome $\left(y_{i}\right)$ for calf $i$ is assumed to be ordered in $k$ categories ( $k=2$ for stillbirth and $k=4$ for calving difficulty and calf size). We assumed an unknown liability $\left(U_{i}\right)$ with $k-1$ unknown thresholds $\left(\mathbf{t}=\left\{t_{1}, \ldots, t_{k-1}\right\}\right)$, which categorized the observed outcome. The model for the liabilities in matrix notation was

$$
\mathbf{U}=\mathbf{X b}+\mathbf{W h}+\mathbf{Z}_{1} \mathbf{s}+\mathbf{Z}_{\mathbf{2}} \mathbf{m g s}+\mathbf{e}
$$

where $\mathbf{U}$ was a vector of liabilities, $\mathbf{b}$ was a vector of fixed effects, $\mathbf{h}$ was a vector of effects of herd-year, $\mathbf{s}$ 
Table 1. Number of observations and frequency of each response category.

\begin{tabular}{llllll}
\hline & & \multicolumn{5}{c}{ Category } \\
\cline { 4 - 6 } Trait & Records & 1 & 2 & 3 & 4 \\
\hline & $($ no.) & & & & \\
Stillbirth $^{1}$ & $1,781,694$ & 0.079 & 0.921 & - & 0.081 \\
Calving difficulty $^{2}$ & $1,466,368$ & 0.466 & 0.421 & 0.031 \\
Calf size $^{3}$ & $1,492,762$ & 0.095 & 0.435 & 0.384 & 0.086 \\
\hline
\end{tabular}

\footnotetext{
${ }^{1} 1=$ Survived $24 \mathrm{~h}$ after birth and $2=$ dead at birth or within $24 \mathrm{~h}$ after birth.

${ }^{2} 1$ = Easy with no help, 2 = easy with assistance, $3=$ difficult but without veterinary assistance, and $4=$ difficult with veterinary assistance.

${ }^{3} 1=$ Small, 2 = just below medium, $3=$ just above medium, and $4=$ large.
}

was a vector of sire effects, mgs was a vector of MGS effects, and $\mathbf{e}$ was a vector of residuals. $\mathbf{X}, \mathbf{W}, \mathbf{Z}_{1}$, and $\mathbf{Z}_{\mathbf{2}}$ were incidence matrices relating the effects to the liabilities. The effects included in $\mathbf{b}$ were cross-classified effects, month of birth, calving age in months, sex $\times$ year of birth, and coefficients for the covariates of breed proportions and degree of heterozygosity. For the proportion of HF genes in the calf and in the dam, the coefficients were $b_{\mathrm{HF}-\text { calf }}$ and $b_{\mathrm{HF}-\mathrm{dam}}$, and for the proportion of heterozygosity between foreign HF and ODBW in the calf and in the dam, the coefficients were $b_{\text {Het- }}$ calf and $b_{\text {Het-dam. }}$.

It was assumed that the liabilities conditional on all of the effects were independent and normally distributed:

$$
\mathbf{U} \mid \mathbf{b}, \mathbf{h}, \mathbf{s}, \mathbf{m g s} \sim \mathbf{N}_{\mathrm{n}}\left(\mathbf{X b}+\mathbf{W h}+\mathbf{Z}_{1} \mathbf{s}+\mathbf{Z}_{2} \mathbf{m g s}, \mathbf{I} \sigma_{\mathrm{e}}^{2}\right) .
$$

If $\mathbf{a}=[\mathbf{s ~ m g s}]^{\prime}$, the expectation of the random effects in the model was

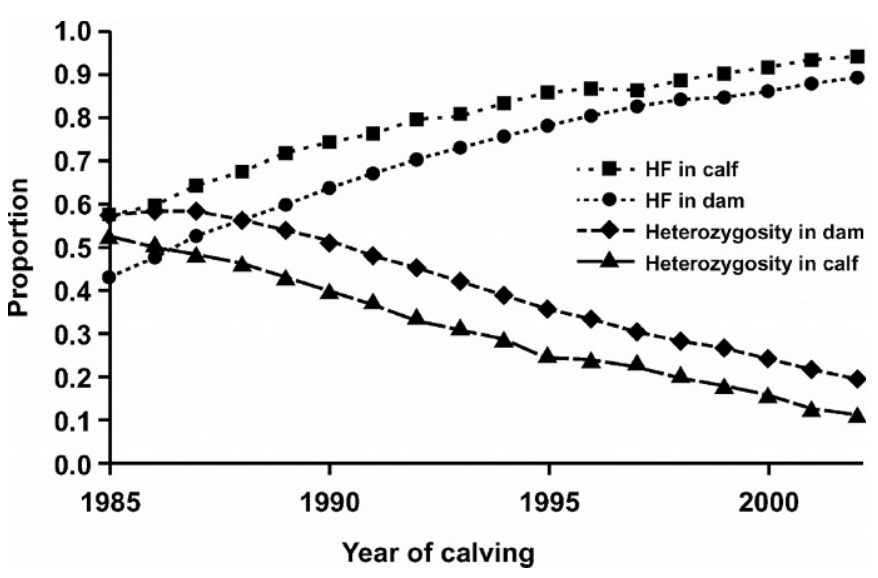

Figure 1. Average proportion of Holstein-Friesian (HF) and heterozygosity between $\mathrm{HF}$ and original Danish Black and White in calves and dams for calvings from 1985 to 2002.

$$
\mathrm{E}\left[\begin{array}{l}
\mathbf{h} \mid \sigma_{\text {hy }}^{2} \\
\mathbf{a} \mid \mathbf{A}, \mathbf{G}_{0} \\
\mathbf{e} \mid \sigma_{\mathrm{e}}^{2}
\end{array}\right]=\left[\begin{array}{l}
0 \\
0 \\
0
\end{array}\right]
$$

with the (co)variance

$$
\operatorname{Var}\left[\begin{array}{l}
\mathbf{h} \mid \sigma_{\mathrm{hy}}^{2} \\
\mathbf{a} \mid \mathbf{A}, \mathbf{G}_{0} \\
\mathbf{e} \mid \sigma_{\mathrm{e}}^{2}
\end{array}\right]=\left[\begin{array}{lll}
\sigma_{\mathrm{hy}}^{2} \mathbf{I} & 0 & 0 \\
0 & \mathbf{G}_{0} \otimes \mathbf{A} & 0 \\
0 & 0 & \sigma_{\mathrm{e}}^{2} \mathbf{I}
\end{array}\right]
$$

where $\mathbf{G}_{0}=\left[\begin{array}{ll}\sigma_{\text {sire }}^{2} & \sigma_{\text {sire,mgs }} \\ \sigma_{\text {sire,mgs }} & \sigma_{\text {mgs }}^{2}\end{array}\right]$ and $\mathbf{A}$ is the additive relationship matrix, which contained 19,925 animals. The additive relationship matrix was created by tracing sire and dam paths as far as possible for 8252 bulls with records as a sire or a MGS.

Dispersion parameters used in this study (Table 2) were based on (co)variances estimated by Hansen et al. $(2003,2004)$. For use in this study, they were scaled to a residual variance equal to one. In all analyses, the last threshold was set to 0 , and therefore $t_{1}$ and $t_{2}$ were estimated for calving difficulty and calf size.

The conditional probability that record $i\left(y_{i}\right)$ was in, e.g., the first category given $\mathbf{b}, \mathbf{h}, \mathbf{s}, \mathbf{m g s}$, and $\mathbf{t}$, was

$$
\begin{aligned}
\mathrm{P}\left(y_{i}\right. & =1 \mid \mathbf{b}, \mathbf{h}, \mathbf{s}, \mathbf{m g s}, \mathbf{t})=\mathrm{P}\left(U_{i}<t_{1} \mid \mathbf{b}, \mathbf{h}, \mathbf{s}, \mathbf{m g s}, \mathbf{t}\right) \\
& =\Phi\left(\mathbf{t}_{1}-\left(\mathbf{x}_{\mathrm{i}} \mathbf{b}+\mathbf{w}_{\mathrm{i}} \mathbf{h}+\mathbf{z}_{1 \mathrm{i}} \mathbf{s}+\mathbf{z}_{2 \mathrm{i}} \mathbf{m g s}\right)\right)
\end{aligned}
$$

where $\Phi$ is the cumulative distribution function of a standard normal distribution, and $\mathbf{x}_{\mathrm{i}}, \mathbf{w}_{\mathrm{i}}, \mathbf{z}_{1 \mathrm{i}}$, and $\mathbf{z}_{2 \mathrm{i}}$ are rows of their respective incidence matrices.

Estimates of location parameters were obtained by use of the software package cblup90iod (Misztal et al., 2002), where algorithms for the threshold models are based on Janss and Foulley (1993) and Hoeschele et al. (1995). To reduce computing time, mixed model equations were solved by iteration on data in combination 
Table 2. Estimates of (co)variance components ${ }^{1}$ based on Hansen et al. (accepted, 2003) used as true parameters in the current study.

\begin{tabular}{llllll}
\hline & $\sigma_{\text {sire }}^{2}$ & $\sigma_{\text {mgs }}^{2}$ & $\sigma_{\text {sire-mgs }}$ & $\sigma_{\text {hy }}^{2}$ & $\sigma_{\mathrm{e}}^{2}$ \\
\hline Stillbirth $^{2}$ & 0.026551 & 0.042882 & 0.014943 & 0.025771 & 1.0 \\
Calving difficulty & 0.035958 & 0.038510 & 0.024057 & 0.186200 & 1.0 \\
Calf size & 0.069428 & 0.028196 & 0.031295 & 0.184657 & 1.0 \\
Stillbirth $^{3}$ & 0.001149 & 0.000532 & 0.001562 & 0.000726 & 0.087822 \\
\hline
\end{tabular}

${ }^{1} \sigma_{\text {sire }}^{2}=$ Variance of sire effects, $\sigma_{\text {mgs }}^{2} \mathrm{k}$ variance of material grandsire effects, $\sigma_{\text {sire-mgs }}=$ covariance between sire and maternal grandsire effect, $\sigma_{\text {hy }}^{2}=$ variance of herd-year effects, $\sigma_{\mathrm{e}}^{2}=$ variance of residuals.

${ }^{2}$ Threshold model.

${ }^{3}$ Linear model.

with the preconditioned conjugate gradient algorithm (Tsuruta et al., 2001).

Genetic trend. Two kinds of additive genetic trends were evaluated. The first trend was the average solutions of genetic effects for all records plotted against the calving year. This trend explains how additive genetic effects have contributed to the phenotypic trend. For each record, a direct effect was calculated as

$$
\hat{\mathrm{s}}_{\text {sire }}+\hat{\mathrm{b}}_{\mathrm{HF}-\text { calf }} \times \mathrm{p}_{\mathrm{HF}-\mathrm{calf}} ;
$$

a maternal effect as

$$
\hat{\mathrm{m}}_{\mathrm{mgs}}-0.5 \hat{\mathrm{s}}_{\mathrm{mgs}}+\hat{\mathrm{b}}_{\mathrm{HF}-\mathrm{dam}} \times \mathrm{p}_{\mathrm{HF}-\mathrm{dam}}
$$

and the sum of all additive genetics effect as

$$
\hat{\mathrm{m}}_{\mathrm{mgs}}+\hat{\mathrm{s}}_{\text {sire }}+\hat{\mathrm{b}}_{\mathrm{HF} \text {-calf }} \times \mathrm{p}_{\mathrm{HF}-\mathrm{calf}}+\hat{\mathrm{b}}_{\mathrm{HF}-\mathrm{dam}} \times \mathrm{p}_{\mathrm{HF}-\mathrm{dam}},
$$

where $\hat{\mathrm{s}}$ is the sire solution for the bull in the subscript, $\hat{m}$ is the MGS solution, $\hat{b}$ is the estimate of the breed effect for the individual given in the subscript, and $\mathrm{p}_{\mathrm{HF}}$ is the proportion of HF genes in the individual given in the subscript.

The second additive genetic trend was evaluated by plotting average PTA against the birth-year of the AI bulls. For the direct trend only, bulls with $>10$ records as a sire were included, and for the maternal trend only, bulls with $>10$ records as MGS were included. The PTA of direct effects were derived as

$$
\hat{\mathrm{s}}+0.5 \hat{\mathrm{b}}_{\mathrm{HF}-\mathrm{calf}} \times \mathrm{p}_{\mathrm{HF}-\mathrm{bull}}
$$

and the PTA of maternal effects were derived as

$$
\hat{\mathrm{m}}-0.5 \hat{\mathrm{s}}+0.5 \hat{\mathrm{b}}_{\mathrm{HF}-\mathrm{dam}} \times \mathrm{p}_{\mathrm{HF}-\mathrm{bull}},
$$

where $\hat{\mathrm{s}}$ is the solution for the bull as sire, $\hat{\mathrm{m}}$ is the solution for the bull as MGS, $\hat{b}$ is the solution of the breed effect given in the subscript, and $\mathrm{p}_{\mathrm{HF}-\mathrm{bull}}$ is the proportion of $\mathrm{HF}$ in the bull.
For both genetic trends, the average solutions in the present year $\left(\right.$ sol lia $\left._{l i}\right)$ were transformed to probability solutions on the observable scale $\left(s_{o b} l_{o b s}\right)$ as

$$
S o l_{o b s}=\Phi\left(\Phi^{-1}(\text { freq })+\operatorname{sol}_{l i a}-\operatorname{sol}_{\text {lia }(\text { base })}\right),
$$

where $\Phi$ is the cumulative distribution function of a standard normal distribution, sol lia(base) $_{\text {is }}$ is the average solution in the year used as reference, and freq is the overall frequency of the trait.

By this method, the trends were presented as the change in probability of, e.g., stillbirth relative to the year of reference. Estimates of effects of breed and heterozygosity were transformed to the observable scale in a similar manner as in Eq. (1) assuming $\operatorname{sol}_{\text {lia(base) }}$ was zero.

Threshold vs. linear model for stillbirth. The evaluation of PTA for stillbirth from the threshold model was compared with PTA from a linear model containing similar effects by estimating correlations between the PTA from the 2 models for classes of bulls with different numbers of records. From the threshold model, both PTA on the liability scale and on the observable scale was used. The PTA were transformed to the observable scale as

$$
P T A_{o b s}=\Phi\left(\Phi^{-1}(\text { freq })+P T A_{\text {lia }}-P T A_{\text {lia(base })}\right)+\text { freq },
$$

where $P T A_{\text {lia(base) }}$ is the average PTA for all bulls with records, and freq is the overall frequency of stillbirth.

The PTA of Danish AI bulls born in 1996 from the linear and the threshold model were plotted. This should visualize the difference between the 2 models for bulls with a typical progeny test for stillbirth at first calving. These bulls had, on average, 77 records (ranging from 29 to 134) as sires of cows. As a sire of calf, the bulls had on average 34 records (ranging from 11 to 69 ) from their test inseminations, but 15 bulls had also later records as a proven bull included. 


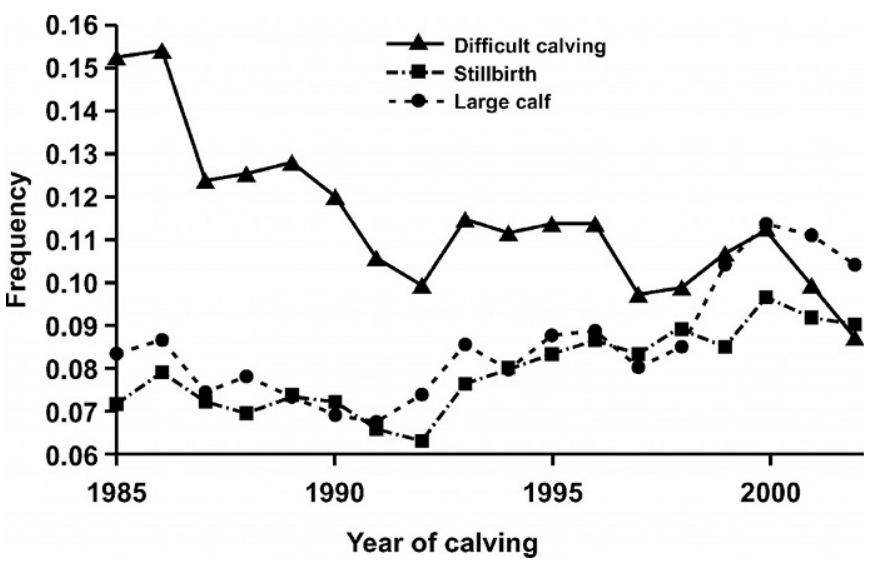

Figure 2. Phenotypic trend in the frequency of stillbirths, difficult calvings, and large calves from 1985 to 2002.

\section{RESULTS}

\section{Phenotypic Trend}

In the period from 1985 to 1992 , the frequency of stillbirths, calving difficulties (category 3 and 4), and of calves scored large (category 4 ) decreased, but after 1992, the frequency of stillbirths and large calves increased (Figure 2). In 1985, the stillbirth rate was 0.071 ; in 1992, it was 0.063 , which increased to 0.090 in 2002.

\section{Genetic Trend}

The additive genetic trends, given as average additive genetic solutions per calving year, are given in Figure 3. For all direct traits, the changes from 1985 to 1992 were small, but in the years after 1992, an increase especially for calving difficulty and calf size were observed. No maternal trends were observed for stillbirth and calf size, but the trend of maternal effects of calving difficulty was favorable as the level in general was decreasing. When all additive genetic effects explained by the model were summed, the levels were slightly decreasing for all traits until 1992, but they all increased in the following years. For the whole period, the change in additive genetic effects in total increased the probability for stillbirth by 0.008 , increased the probability for a difficult calving by 0.007 , and increased the probability for a large calf by 0.049 .

The average levels of direct and maternal PTA of stillbirth, calving difficulty, and calf size for the AI bulls have, in general, been increasing (Figure 4). For bulls born from 1983 to 1999, the increase in PTA of direct effects on the observable scale was 0.018 for a difficult calving, 0.022 for a large calf, and 0.004 for a stillborn calf. No trend for the AI bulls was observed in the level of maternal effects for calving difficulty and calf size,
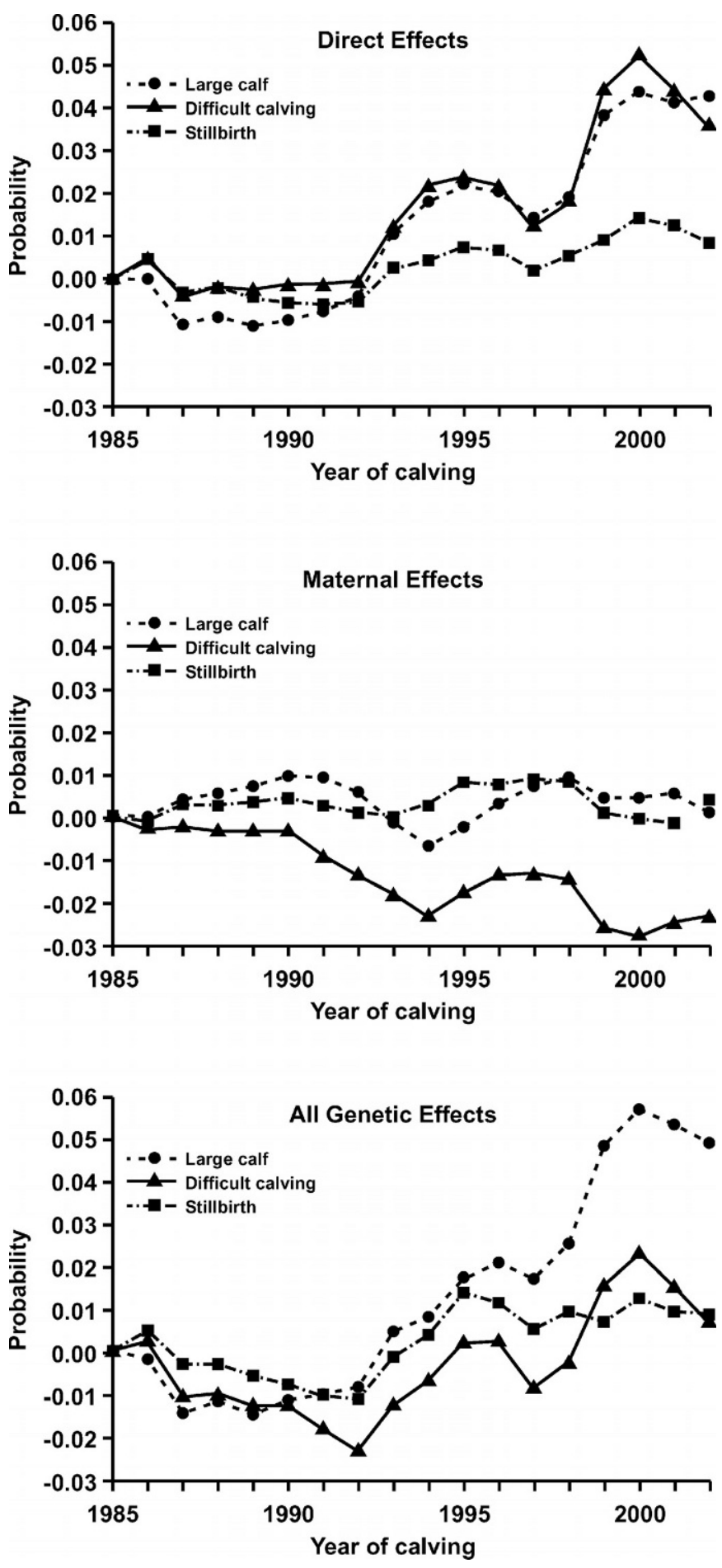

Figure 3. Change on the observable scale of direct, maternal, and all genetic effects for a large calf, a difficult calving, and stillbirth in the records from 1985 to 2002.

but the trend was unfavorable for the maternal effect of stillbirth. The average PTA of the maternal effect of stillbirth were on the observable scale 0.014 higher for bulls born in 1997 compared with bulls born in 1983 . 

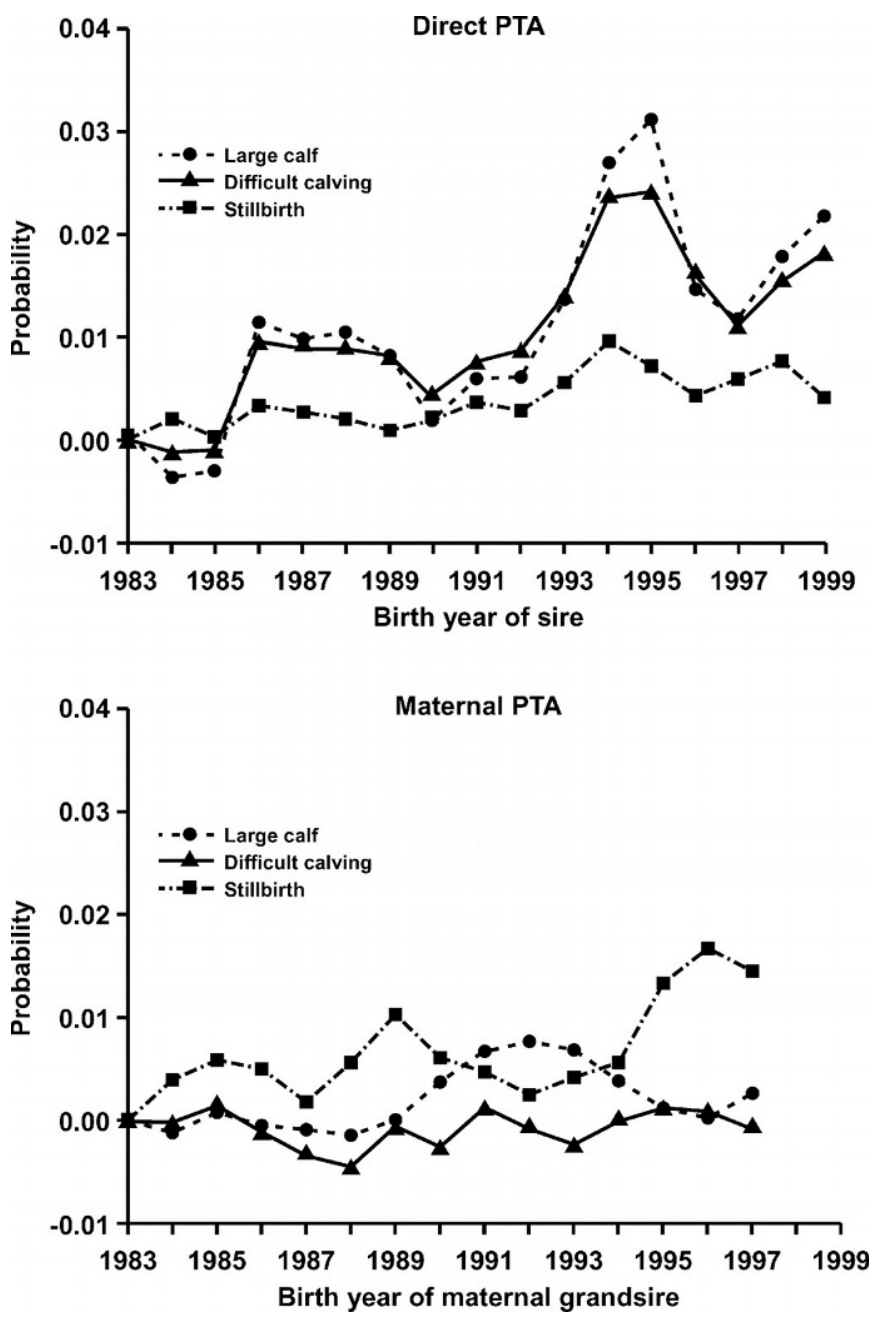

Figure 4. Change on the observable scale of direct and maternal PTA for a large calf, a difficult calving, and stillbirth for all sires and for maternal grandsires with $>10$ records included.

\section{Breed and Heterosis}

For all traits, the additive genetic effects in the calf were higher for $\mathrm{HF}$ than for ODBW. The estimated effect of HF from the threshold model was (on the ob- servable scale) 0.04 higher for stillbirths, 0.11 higher for difficult calvings, and 0.10 higher for large calves (Table 3). The maternal breed effects were smaller. On the observable scale, the additive genetic effect of $\mathrm{HF}$ in the dam was 0.01 higher for stillbirth and 0.04 less for difficult calvings than ODBW but almost equal for calf size. Therefore, the increasing percentage of $\mathrm{HF}$ genes contributed to the additive genetic trends. For calves born from 1985 to 2002 , the effect of the increasing proportion of $\mathrm{HF}$ genes was $75 \%$ of the total change in direct effects of calf size and $96 \%$ of the total change in directs effects of calving difficulty. For direct effects of stillbirth, the undesired effect of the increasing proportion of $\mathrm{HF}$ was $75 \%$ larger than the total change in direct effects. This meant that some genetic improvement within the breeds was performed.

The estimated breed effects of stillbirth from the threshold model and from the linear model differed. From the linear model, the additive genetic effect of $\mathrm{HF}$ in the calf was 0.01 and 0.02 for the effect in the dam.

The regression coefficients for the degree of heterozygosity $\left(b_{\text {Het-calf }}\right.$ and $b_{\text {Het-dam }}$ ) were in general all small. These regression coefficients can be interpreted as the effect of animals with $100 \%$ heterozygosity ( $\mathrm{F}_{1}$ cross) compared with animals with no heterozygosity (purebreds). The effect in the calf ( $b_{\text {Het-calf }}$ ) was (on the observable scale) between 0.00 and 0.01 for all traits. The maternal heterozygosity was not important for stillbirth and calf size, but the probability of a difficult calving was 0.02 lower for dams with $100 \%$ heterozygosity compared with purebred dams.

\section{Threshold vs. Linear Model of Stillbirth}

The correlations between PTA for stillbirth from the linear and the threshold model were high (0.96 to 1.00) for both direct and maternal effects (Table 4). The correlations were generally highest for bulls with most records. The PTA from the linear model were slightly more correlated with PTA from the threshold model expressed on the observable scale than with PTA expressed on the liability scale.

Table 3. Estimates on the observable scale of the effect of Holstein-Friesian (HF) relative to original Danish Black and White (ODBW) and of the effect of heterozygosity between HF and ODBW (heterosis) relative to no heterozygosity.

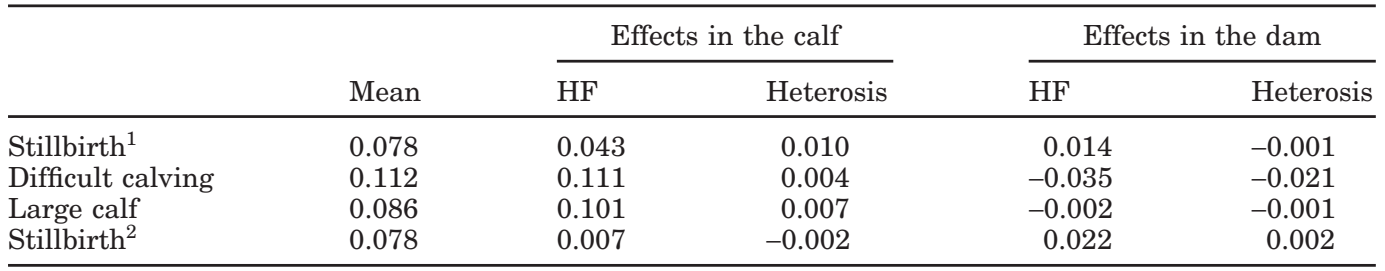

${ }^{1}$ Threshold model.

${ }^{2}$ Linear model. 
Table 4. Correlations between PTA from the linear model and PTA from the threshold model depending on the number of observations per sire for the direct effect and per maternal grandsire (MGS) for the maternal effect. The PTA for the threshold model were given on the liability scale (Lia) and the observable scale (Obs).

\begin{tabular}{|c|c|c|c|c|c|c|}
\hline \multirow[b]{2}{*}{ Records } & \multicolumn{3}{|c|}{ Direct PTA } & \multicolumn{2}{|c|}{ Maternal PTA } & \multirow[b]{2}{*}{ Obs } \\
\hline & Sires & Lia & Obs & MGS & Lia & \\
\hline & (no.) & & & (no.) & & \\
\hline $1-10$ & 687 & 0.964 & 0.967 & 404 & 0.964 & 0.971 \\
\hline $11-25$ & 2040 & 0.975 & 0.978 & 176 & 0.971 & 0.977 \\
\hline $26-50$ & 2442 & 0.981 & 0.984 & 355 & 0.977 & 0.985 \\
\hline $51-100$ & 1186 & 0.984 & 0.987 & 4471 & 0.986 & 0.990 \\
\hline $101-1000$ & 350 & 0.985 & 0.991 & 1081 & 0.980 & 0.987 \\
\hline$>1000$ & 188 & 0.990 & 0.997 & 204 & 0.981 & 0.989 \\
\hline
\end{tabular}

The association between PTA from the linear model and the threshold model for Danish AI bulls born in 1996 were high (Figure 5). The correlation was 0.987 for the direct effect and 0.995 for the maternal effect. The range of PTA was larger for the maternal effect than for direct effect. From the threshold model, the PTA ranged from 0.045 to 0.182 for the maternal effect and from 0.050 to 0.116 for the direct effect.

The genetic trends from the linear and the threshold models were comparable. From the linear model, the difference in PTA for the direct effect of stillbirth between bulls born in 1983 and 1999 was 0.005 and for the maternal PTA between bulls born in 1983 and 1997 was 0.015 (results not shown). These trends were in close agreement with the trends obtained with the threshold model (Figure 4).

For both the threshold and the linear model, the ranking of sires was almost identical whether effects of breed and heterosis were included or excluded from the model. The correlations between PTA were all higher than 0.996 for both maternal and direct effects (results not shown).

\section{DISCUSSION}

In the Danish Holstein population, the introgression of $\mathrm{HF}$ has happened by an intense use of $\mathrm{HF}$ sires (mainly from North America) as sires of sons in Denmark. Therefore, these sires of sons have a large impact on the genetic trend, especially for the genetic trend of the AI bulls. In general, the sires of sons with large impact on the Danish Holstein population is similar to the sires of sons with large impact on the Holstein population in the US, shown by Hansen (2000). As examples of sires, Starbuck, Blackstar, and Luke with 180,301 , and 111 AI bulls as sons in the data set, have increased the direct effects of calf size and of stillbirth. The unfavorable trend of maternal effects of stillbirth for the AI bulls born in 1995 to 1997 was also caused by few heavily used sires. Therefore, the estimates of
HF have to be interpreted as the HF genetics used in Denmark. It is not possible to conclude from this study that HF in general is worse for stillbirth than ODBW. However, it can be concluded that the chosen sires of sons from the HF population has contributed to increase the genetic level of stillbirth in Danish AI bulls and in the Danish Holstein population.

An unfavorable additive genetic trend for both the direct and maternal effect of stillbirth was found when evaluating all records from 1985 to 2002. The increase in direct effects of stillbirth was associated with an increase in direct effects of calving difficulty and especially calf size. It can be concluded that the larger calves of HF compared with ODBW have resulted in more calving difficulties and more stillbirths in the Danish Holstein population. Supporting this conclusion is the high genetic correlation ( 0.69 to 0.93 ) between direct effects of stillbirth and calving difficulty and stillbirth and calf size (Hagger and Hofer, 1990; Hansen et al., 2003).

The effect of $\mathrm{HF}$ additive genes in the dam was unfavorable for stillbirth but favorable for calving difficulty. This means that HF had maternal effects, which affects the survival of the calf (or fetus) negatively, but these effects were not due to increased calving difficulty. Instead, these effects may relate to a poorer environment in the uterus for the survival of the calf. Also, the total genetic change per calving year was clearly favorable for the maternal effect of calving difficulty but slightly unfavorable for the maternal effect of stillbirth. These findings are in contrast to the positive genetic association between maternal effects of stillbirth and calving difficulty (Danish Cattle Federation, 2003; Hansen et al., 2003; Steinbock et al., 2003). Future studies of factors involved in this maternal effect of stillbirth seem necessary because the causes of stillbirths not associated with calving difficulty are unknown (Meijering, 1984).

Complex vertebral malformation (CVM), which leads to abortions and stillbirth, has had a small influence 

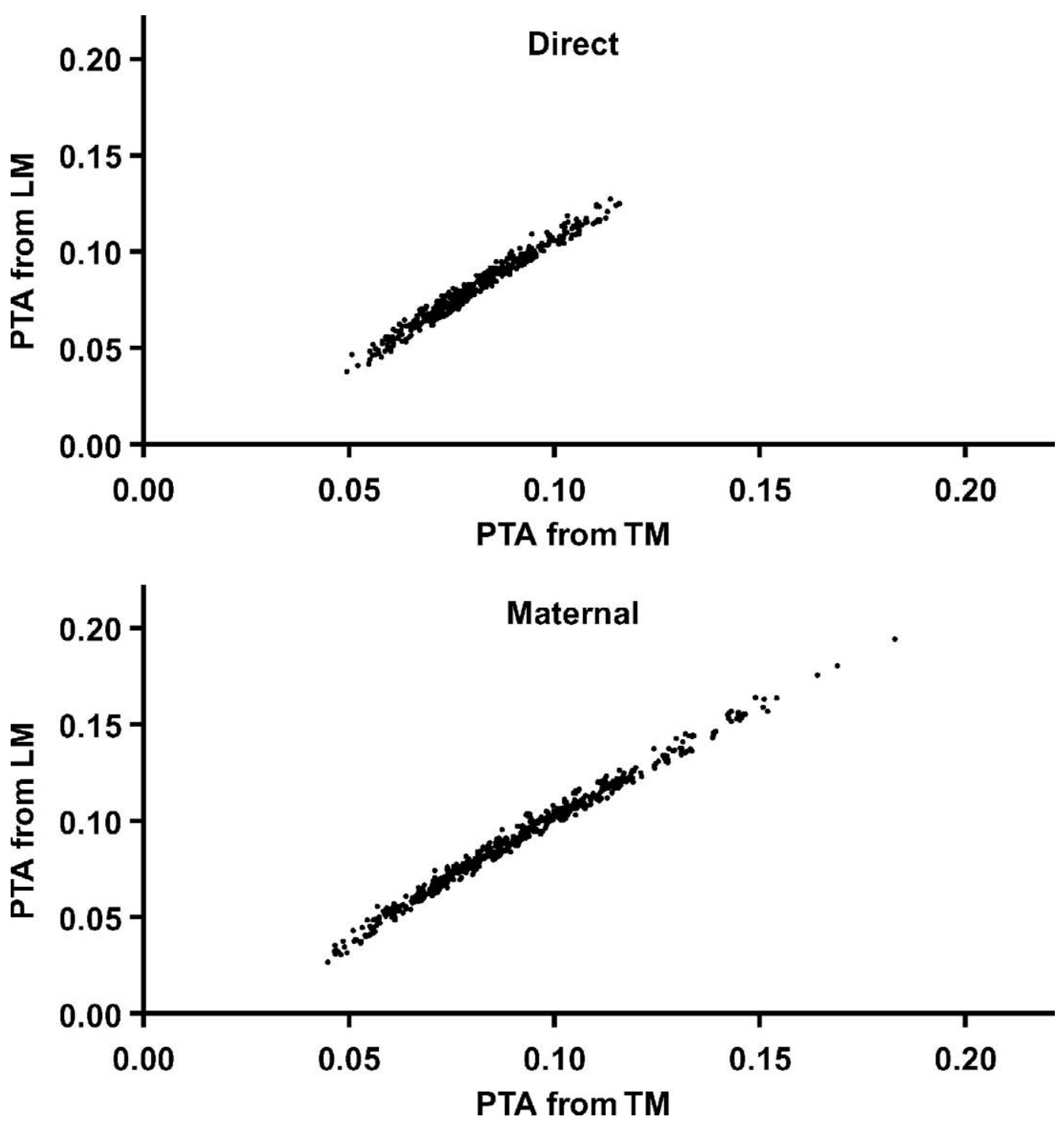

Figure 5. Association between PTA from the linear model (LM) and PTA from the threshold model (TM) (on the observable scale) for direct and maternal effects of stillbirth for all Danish AI bulls born in 1996.

on the genetic trend in stillbirth. In the data set, all sires were classified as free of CVM, possible carrier of CVM, and carrier of CVM. Less than $3 \%$ of the calves had sires with unknown status (possible carrier). The genetic trend of direct effects of all calves compared with the genetic trend of calves with a sire tested as CVM carrier is presented in Figure 6. The genetic trend is almost identical for calves with sires tested free of CVM as the genetic trend for all of the calves. However, in the end of the period, the genetic level of calves with CVM increased. This result is apparently because the frequency of cows carrying CVM had increased, which resulted in more CVM homozygous fetuses and calves. The relatively low impact of CVM on the genetic trend can be explained by the fact that $77 \%$ of CVM homozygous fetuses were aborted before $260 \mathrm{~d}$ after insemination and, therefore, were not recorded as stillbirths (Nielsen et al., 2003).

To understand whether other lethal recessive genetic effects appeared in the population, the distribution of PTA for sons of the most used sires of sons were examined for any bimodal distribution. However, for both the direct and the maternal PTA of stillbirth, no indications of any bimodal distributions were found.

As expected from other studies of calving traits using sire MGS models (Weller et al., 1988; Hagger and Hofer, 1990), relatively small differences in PTA from the linear and the threshold model were found in this study. 


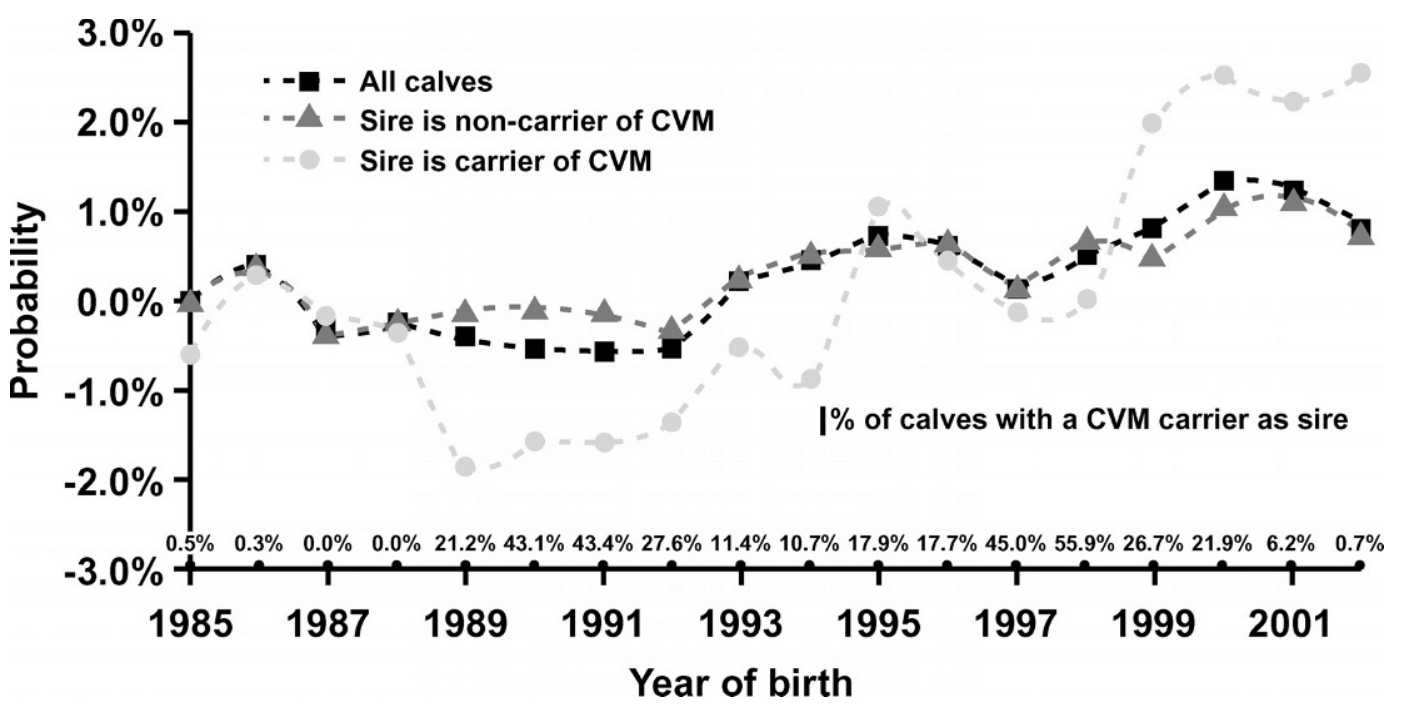

Figure 6. Genetic change of direct effects for all calves, for calves where the sire is a carrier of complex vertebral malformation (CVM), and for calves where the sire is free of CVM. The percentage of calves with a CVM carrier as sire is given for each year.

However, for traits with a low number of records per sire (e.g., direct effects of stillbirth and calving difficulty at first calving), the threshold model might give better prediction, as the difference between the models was largest with small progeny groups. Ramirez-Valverde et al. (2001) concluded that the linear sire MGS model performed as good as the threshold sire MGS model, but when fitting an animal model, the threshold model was superior. Therefore, the need for a genetic evaluation with a threshold model does not seem to be strong as long a sire MGS model is fitted, but when fitting an animal model, the superiority of a threshold model might be larger.

Despite small differences between PTA from the linear and the threshold sire MGS models, a notable difference in breed estimates was found in this study, which indicates that some effects might not be estimated adequately when a linear model is used for categorical traits.

When transforming estimates on the liability scale to the observed scale, a mean probability must be chosen. We decided to use the overall frequency, as this analysis is a description of the past. If the models should be used to predict future records, a more recent frequency (e.g., the last year) would be a better choice. For stillbirth, this would have resulted in a higher frequency, which would give larger differences between the PTA on the observed scale.

By including the breed effects in the model, the calves and dams were corrected for all of the additive genetic differences between the two breeds. It was possible to infer a larger part of the additive genetic effects in the calves and dams than if the breed effects were omitted.
However, an animal model with genetic groups would be preferable to take account of all additive genetic effects in the individuals.

The present study ignored twins, abortions, calves with unknown sex, calves with unknown sires or MGS, and calves with privately owned service sires or MGS. Therefore, the presented stillbirth rate is not representative for the whole population. If all calvings were included, the stillbirth rate at first calving was $12 \%$ in 2002. Philipsson and Steinbock (2003) argue a stillbirth rate around 11 to $12 \%$ is alarming. Other breeds such as the Danish Red, Danish Jersey, and the Swedish Red and White have shown that it is possible to have a considerable lower stillbirth rates (5 to 6\%) at first calving (Nielsen et al., 2002; Philipsson and Steinbock, 2003). Based on a considerable genetic variation of stillbirth in Holsteins (Steinbock et al., 2003; Hansen et al., 2004), it is possible to reduce the stillbirth rate by selection of sires. Today, only the maternal effects of stillbirth and calving difficulty are included in the breeding goal for Danish Holsteins. Dekkers (1994) showed that the inclusion of direct effects in the breeding goal is even more important than maternal effects. Therefore, the inclusion of direct effects of stillbirth and calving difficulty in the Danish breeding goal needs to be examined.

\section{CONCLUSION}

An unfavorable trend of direct and maternal genetic effects for stillbirth in the Danish Holstein population was found. A major reason for this was an intense use of selected HF sires, which has increased the proportion 
of HF genes in the Danish population. These HF genes have increased the direct effects of calf size, calving difficulty, and stillbirth. The HF genes have increased the maternal effect for stillbirth despite the desirable maternal effect of the HF genes for calving difficulty.

\section{REFERENCES}

Danish Cattle Federation. 2003. Principles of Danish Cattle Breeding. The Danish Agricultural Advisory Center, Aarhus, Denmark. http://www.lr.dk/kvaeg/diverse/principles.pdf. Accessed July 10, 2003.

Dekkers, J. C. M. 1994. Optimal breeding strategies for calving ease. J. Dairy Sci. 77:3441-3451.

Dematawewa, C. M. B., and P. J. Berger. 1997. Effect of dystocia on yield fertility and cow losses and an economic evaluation of dystocia scores for Holsteins. J. Dairy Sci. 80:754-761.

Ducrocq, V. 2000 Calving ease evaluation of French dairy bulls with a heteroskedastic threshold model with direct and maternal effects. Proc. 2000 Interbull Mtg. in Bled, Slovenia, May 14-15, 2000. Interbull Bull. 25:1-8.

Gianola, D., and J. L. Foulley 1983. Sire evaluation for ordered categorical data with a threshold model. Genet. Sel. Evol. 15:201-224.

Hagger, C., and A. Hofer. 1990. Genetic analyses of calving traits in the Swiss Black and White, Braunvieh and Simmental Breeds by REML and MAPP procedures. Livest. Prod. Sci. 24:93-107.

Hansen, L. B. 2000. Consequences of selection for milk yield from a geneticist's viewpoint. J. Dairy Sci. 83:1145-1150.

Hansen, M., M. S. Lund, J. Pedersen, and L. G. Christensen. 2003. Heritabilities and genetic relationships between gestation length, stillbirth, size of calves, and calving problems in Danish Holstein cows. 54th Annu. Mtg. Eur. Assoc. Anim. Prod., Roma, Italy, August 31-September 3, 2003. Session G4.

Hansen, M., M. S. Lund, J. Pedersen, and L. G. Christensen. 2004. Genetic parameters for stillbirth in Danish Holstein cows using a Bayesian threshold model. J. Dairy Sci. 87:706-716.

Harbers, A., L. Segeren, and G. de Jong. 2000. Genetic parameters for stillbirth in the Netherlands. Proc. 2000 Interbull Mtg., Bled, Slovenia, May 14-15, 2000. Interbull Bull. 25:117-122.

Hoeschele, I., B. Tier, and H. U. Graser. 1995. Multiple trait genetic evaluation for one polychotomous trait and several continuous traits with missing data and unequal models. J. Anim. Sci. 73:1609-1627.
Janss, L. L. G., and J. L. Foulley. 1993. Bivariate analysis for one continuous and one threshold dichotomous trait with unequal design matrices and an application to birth weight and calving difficulty. Livest. Prod. Sci. 33:183.

Meijering, A. 1984. Dystocia and stillbirth in cattle-A review of causes, relations and implications. Livest. Prod. Sci. 11:143-177.

Meyer, C. L., P. J. Berger, J. R. Thompson, and C. G. Sattler. 2001. Genetic evaluation of Holstein sires and maternal grandsires in the United States for perinatal survival. J. Dairy Sci. 84:12461254 .

Misztal, I., S. Tsuruta, T. Strabel, B. Auvray, T. Druet, and D. H. Lee. 2002. Blupf90 and related programs. Proc. 7th World Congr. Appl. Livest. Prod., Montpellier, France. Commun. No. 28-07.

Nielsen, U. S., G. P. Aamand, O. Andersen, C. Bendixen, V. H. Nielsen, and J. S. Agerholm. 2003. Effects of complex vertebral malformation on fertility traits in Holstein cattle. Livest. Prod. Sci. 79:233-238.

Nielsen, L. A. H., A. Glacius, A. Fogh, and F. Skjøth. 2002. Dødelighed hos kalve af malkerace. Rep. No. 102. Danish Cattle, Udkærsvej 15, Aarhus, Denmark.

Pasman, E., and F. Reinhardt. 2002. International genetic evaluation for calving ease and stillbirth. Proc. 2002 Interbull Mtg., Interlaken, Switzerland, May 2002. Interbull Bull. 29:49-54.

Phillipsson, J., and L. Steinbock. 2003. Definition of calving traitsResults from Swedish research. Proc. Interbull Tech. Workshop, Beltsville, MD, March 2003. Interbull Bull. 30:71-74.

Ramirez-Valverde, R., I. Misztal, and J. K. Bertrand. 2001. Comparison of threshold and linear models for calving difficulty in beef cattle. J. Anim. Sci. 79:333-338.

Steinbock, L., A. Näsholm, B. Berglund, K. Johansson, and J. Philipsson. 2003. Genetic effects on stillbirth and calving difficulty in Swedish Holsteins at first and second calving. J. Dairy Sci. 86:2228-2235.

Tsuruta, S., I. Misztal, and I. Strandén. 2001. Use of preconditioned conjugate gradient algorithm as a generic solver for mixed-model equations in animal breeding applications. J. Anim. Sci. 79:1166-1172.

Wang, C. S., R. L. Quaas, and E. J. Pollak. 1997. Bayesian analysis of calving ease scores and birth weights. Genet. Sel. Evol. 29:117-143.

Weller, J. I., I. Misztal, and D. Gianola. 1988. Genetic analysis of dystocia and calf mortality in Israeli-Holsteins by threshold and linear models. J. Dairy Sci. 71:2491-2501.

Wiggans, G. R., I. Misztal, and C. P. Van Tassel. 2003. Calving ease (co)variance components for a sire-maternal grandsire threshold model. J. Dairy Sci. 86:1845-1848. 